\title{
The Usage of Cryopreservation and Synthetic Seeds on Preservation for Plant Genetic Resources
}

\author{
Tolga İzgü ${ }^{1}$ and Yeşim Yalçın Mendii ${ }^{2 *}$ \\ ${ }^{1}$ Department of Horticulture, University of Ege, Turkey \\ ${ }^{2}$ Department of Horticulture, University of Çukurova, Turkey
}

Submission: April 18, 2017; Published: May 02, 2017

*Corresponding author: Yeşim yalçın mendi, Department of Horticulture, Faculty of Agricultre, University of Çukurova, 01330, Sarıçam, Adana, Turkey, Email: ymendi@gmail.com

\section{Introduction}

The endangered and endemic species of plant biodiversity in both nature and agricultural fieldshave led the flora to look for alternatives to in situ conservation. Therefore, cryopreservation is a useful tool for long-term storage of plant germplasmfor next generations, requiring only a minimum of space and maintenance. With increasing interest in the genetic engineering of plants, the preservation of cell lines (callus or protoplast) and somatic embryos with incomparable attributes is assuming highlysignificance. Latterly, cryopreservation was reported to offer real hope for enhancing the preservation of endangered and endemic plants.

Cryopreservation techniques are based upon different tissues of plant storage such as apical or axillary shoot tips, meristems, scions, seeds, spores, gametophytes, rhizomes, zygotic and somatic embryos, pollens, embryogenic callus lines at ultra-low temperature of liquid nitrogen $\left(\mathrm{LN},-196^{\circ} \mathrm{C}\right)$. The major advantage of this procedure is to diminish in vitro culture costs, required space, contamination and somaclonal variation or genetic altering risk. The long-term conservation of embryogenic cell lines may be a valuable tool in genetic engineering.

Generally two types of cryoprotectants are used for cryopreservation, those that penetrate the plasma membrane (e.g., Dimethyl sulfoxide (DMSO) and glycerol), and the non-penetrating chemicals (e.g. polyethylene glycol (PEG), polyethylene glycol (EG) and sucrose). Synthetic/encapsulated seed technology involving calcium alginate encapsulation of in vitro or in vivo generated explants proved to be are liable system to deal with propagation and cryostorage. Cryopreservation techniques are separated in to two main groups: traditional (two step freezing) and modern (one step freezing) techniques. There are several combinations of the cryopreservation techniques. The combinations of these techniques are now directly applicable for many plant species. These techniques:
A. Controlled rate cooling(two-step freezing, controlledrate freezing or slow cooling)

B. Vitrification (with plant vitrification solution-2 "PVS2") [1].

C. *PVS2 including $30 \%$ glycerol $(\mathrm{w} / \mathrm{v})+15 \%$ ethylene glycol $(\mathrm{w} / \mathrm{v})+15 \%$ dimethylsulfoxide (DMSO; w/v) in MS (Murashige and Skoog, 1962) basal medium (plant growth regulators free) containing $0.4 \mathrm{M}$ sucrose (pH 5.8)

D. Encapsulation/vitrification

E. Encapsulation/dehydration

F. Droplet method

G. Dessication (Laminal flow cabinet or silica gel)

H. V-Cryo-plate and D-Cryo-plate procedures

Slow cooling is provided by a device named «programmable freezer». In this system, the parameters can be adjusted easily such as starting temperature, freezing rate, final temperature and waiting time. Because this method is expensive, lower technology (Nalgene freezing container, Mr. Frosty®) can be used in stead of it. Vitrification is very effecitve method for the cryopreservation of plant materials because it would avoid the potentially impairing effects of intracellular and extracellular freezing. This method can be defined as the transition of water directly from the liquid phase into an amorphous phase, while avoiding the formation of crystalline ice. Vitrification is commonly used for embryogenic callus lines, meristems, somatic embryos and etc. in LN. In vitrification methods, embryogenic callus/somatic embryos can be sufficiently dehydrated with PVS2 at $25^{\circ} \mathrm{C}$ or $0{ }^{\circ} \mathrm{C}$ without causing injury to enable vitrification upon rapid cooling in LN. 
Encapsulatedor synthetic seedshave advantages such as easy handling, storage, transferring, germ plasm conservation of elite or endemic plant species for cryopreservation, exchange of non-contaminated plant materials among laboratories, gene banks and industries. For preparation of alginate beads, the explants are suspended in calcium- free liquid MS basal medium with $3-4 \%(w / v)$ sodium alginate (generally using low viscosity) [2]. This solution generally contains low level sucrose in the MS basal medium. In some cases, explants can also be encapsulated in a MS medium with a slightly higher sucrose concentration. The mixture is dropped with a pipette into liquid culture medium containing calcium chloride $(100 \mathrm{mM} \mathrm{CaCl} 2)$. This causes the polymerization of alginate in presence of an raised concentration of calcium, hence producing beads around the explants. These synthetic beads are usually 4 or $5 \mathrm{~mm}$ in diameter and include one shoot tip,somatic embryos (such as globular, heart, torpedo and cotyledon stages or microcorm) or embriogenic callus clusters. They are waited in the $\mathrm{CaCl} 2$ solution for $20-30 \mathrm{~min}$ after the beads are formed to polymerization. First application of encapsulation dehydration technique was developed for invitro pear and potatoaxillary shoot tips. This method is based on the preservation of synthetic seeds, The standard vitrification protocol takes place in cryotubes while the droplet method is made on aluminum foil strips [3]. The droplet method with PVS2 or DMSO is also used for cryopreservation of several plant types. Drops of different concentration of DMSO or PVS2 solution are placed on aluminum foil strips and immersed into liquid nitrogen (LN). Although the cooling rate is extremely fast, no vitrification is determined within the plant tissues or cell.

The desiccation technique, either in a laminar airflow cabinet or over silica gel, is used for cryopreservation of somatic embryos, synthetic seeds or embryonic axes. Because this method is simple and easy handling, it should be tried first before testing the other techniques. The optimum moisture for cryopreservation ranges from 8 to $20 \%$ (time of desiccation, usually 1-2h) depending on explant type and the species. There are two desiccation techniques: dehydration under the air current of a laminar flow cabinet or dehydration in sealed containers with silica gel. Desiccation under the laminar flow can produce variable desiccation rates depending on the airflow rate, air temperature, and relative humidity [2].

A new cryopreservation methods based on vitrification and air dehydration of explants placed on aluminum cryo-plates, named the V-cryo-plate and D-cyo-plate technique. Recently, a vitrification protocol using the aluminum v-cryo-plate method has been reported [5-8]. The cryo-plate method has two main advantages:

\section{A. A user-friendly procedure and,}

B. Higher cooling and warming rates of treated explants are possible by directly immersion in LN [4] Consequently, efficient regrowth was obtained after cryopreservation of the various plant explants [9]. In the D cryo-plate method, shoot tips or buds attached to the cryo-plates are dehydrated in the laminar air flow cabinet or over silica gel after loading treatment with glycerol and sucrose solution for inducing tolerance to dehydration. Capacious samples consisting of buds and basal stems can be used for the materials in this technique. So it is a practical and efficient method for cryopreservation [4,10-13] Figure 1.

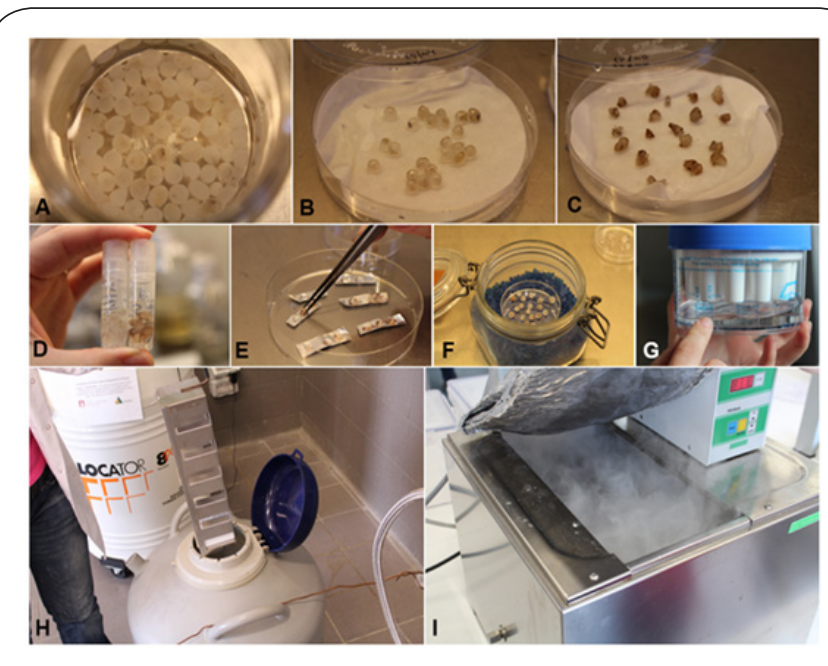

Figure 1: Basic steps of the different cryopreservation techniques, A) Polymerization of synthetic seeds in $\mathrm{CaCl}$ 2solution (100 $\mathrm{mM}), \mathrm{B}-\mathrm{C})$ Preculture ofsynthetic seeds and somatic embryos on MS medium with $0.3 \mathrm{M}$ sucrose before immersion in LN, D) Treatment with PVS2 solution of synthetic seeds and somatic embryos in cryovials,E) Somatic embryosplaced on aluminium plates (Droplet method), F) Dessication with silica gel of synthetic seeds, G) Isopropanol inclueded in a Mr Frosty ${ }^{\circledR}$ (Nalge Nunc, Rochester, New York, USA) unit provides a $1^{\circ} \mathrm{C} \cdot$ per min. cooling rate (Controlled-rate freezer), $\mathrm{H}-\mathrm{I}$ ) Samples are directlyimmersion into liquid nitrogen $\left(\mathrm{LN},-196^{\circ} \mathrm{C}\right.$ at least $\left.1 \mathrm{~h}\right)$ and the standard thawing cryogenic vial from the storage container to a water bath held at $35-40^{\circ} \mathrm{C}$.

\section{References}

1. Sakai A, Kobayashi S, Oiyama I (1990) Cryopreservation of nucellar cells of navel orange (Citrus sinensis Osb. var. brasiliensis Tanaka) by vitrification. Plant Cell Rep 9(1): 30-33.

2. Engelmann F, Arnao MTG, Wu Y, Escobar R (2008) Development of encapsulation dehydration. In Plant cryopreservation: A practical guide, Springer, New York, USA, pp. 59-75.

3. Panis B, Piette B, Swennen R (2005) Droplet vitrification of apical meristems: A cryopreservation protocol applicable to all Musaceae. Plant Sci 168: 45-55.

4. Niino T, Watanabe K, Nohara N, Rafique T, Yamamoto SI, et al. (2014) Cryopreservation of mat rush lateral buds by air dehydration using aluminum cryo-plate. Plant Biotechnology 31(3): 281-287.

5. Yamamoto ST, Rafique K, Fukui K, Sekizawa A, Koyama T, et al. (2012) Development of an effective cryopreservation protocol using aluminum cryo-plates for in vitro-grown shoot tips of mulberries (Morus spp.) originated from the tropics and subtropics. Sanshi-Konchu Biotec 81(1): 57-62.

6. Yamamoto S, Rafique T, Fukui K, Sekizawa K, Niino T (2012b) V-Cryoplate procedure as an effective protocol for cryobanks. Case study of mint cryopreservation. CryoLett 33(1): 12-23. 
7. Yamamoto SF, Fukui T, Rafique NI, Khan CR, Castillo Martinez K, et al. (2011a). Cryopreservation of in vitro-grown shoot tips of strawberry by the vitrification method using aluminum cryo-plates. Plant Genet Resour Charact Util 10: 14-19.

8. Yamamoto S, Rafique T, Priyantha WS, Fukui K, Matsumoto T, et al. (2011) Development of a cryopreservation procedure using aluminum cryo-plates. CryoLett 32(3): 256-265.

9. Niino T, Yamamoto S, Fukui K, Martínez CRC, Arizaga MV, et al. (2013) Dehydration improves cryopreservation of mat rush (Juncus decipiens Nakai) basal stem buds on cryo-plates. CryoLett 34(6): 549-560.

10. Matsumoto T, Yamamoto SI, Fukui K, Rafique T, Engelmann F, et al (2015) Cryopreservation of Persimmon Shoot Tips from Dormant
Buds Using the D Cryo-plate Technique. The Horticulture Journal 84 (2): 106-110

11. Sakai A, Kobayashi S, Oiyama I (1991) Cryopreservation of nucellar cells of navel orange (Citrus sinensis 0 sb.) by a simple freezing method. Plant Sci 74: 243-248.

12. Sakai A, Kobayashi S, Oiyama I (1991b) Survival by vitrification of nucellar cells of navel orange (Citrus sinensis var. brasiliensis Tanaka) cooled to $-196^{\circ} \mathrm{C}$. J Plant Physiol 137: 465-470.

13. Fahy GM, Wowk B (2015) Principles of cryopreservation by vitrification.Cryopreservation and Freeze-Drying Protocols, Methods in Molecular Biology. Springer, New York, USA, pp. 8221-8282.

\section{Your next submission with Juniper Publishers} will reach you the below assets

- Quality Editorial service

- Swift Peer Review

- Reprints availability

- E-prints Service

- Manuscript Podcast for convenient understanding

- Global attainment for your research

- Manuscript accessibility in different formats

( Pdf, E-pub, Full Text, Audio)

- Unceasing customer service

Track the below URL for one-step submission https://juniperpublishers.com/online-submission.php 